\title{
A girl with an unusual tumour recurrence
}

\author{
U A R S Ranawaka ${ }^{1}$, A K Lamahewage ${ }^{2}$ \\ Sri Lanka Journal of Child Health, 2010; 39: 150-151
}

(Key words: Sacrococcygeal teratoma, girl)

An 11-year-old girl attended the surgical clinic with an incidentally detected right inguinal mass of 5 days duration. On examination, a firm inguinal lymph node mass was palpable. The rest of the clinical examination was normal.

\section{Previous history}

At 5 years of age, a vascular malformation was detected over her left thigh. An ultrasound scan of the abdomen detected a possible sacro-coccygeal teratoma. Surgical excision was done via posterior sagittal and Pfannenstiel incisions. The findings were:

- $3 \times 2 \mathrm{~cm}$ size cystic mass anterior to the sacrum pushing the common iliac vessels laterally but not adherent to any structure.

- A mobile lump firmly adherent to coccyx and felt per rectally.

The lumps were removed en-masse. Histology revealed non seminomatous germ cell tumour, a malignant teratoma consisting entirely of papillary carcinoma of thyroid origin.

After an uneventful recovery, she was referred for an oncological opinion. Conservative management with regular clinic review was planned. She had defaulted follow up. Until the incidental finding of the inguinal mass this time, she was asymptomatic.

\section{Current management}

An ultrasound scan, done in view of the inguinal mass, showed a $4 \mathrm{~cm}$ size heterogeneous mass in the right groin with areas of cystic degeneration and calcification. In the left groin a $1.2 \times 0.6 \mathrm{~cm}$ size lymph node mass was seen. The impression

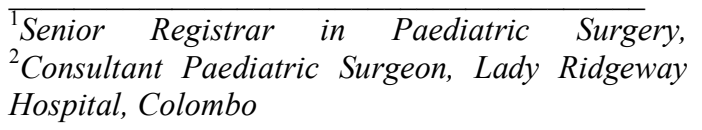

(Received 5 November 2009; Accepted after revision on 18 December 2009) was of a recurrence of the teratoma. There were no metastases in the rest of the abdomen. The chest $\mathrm{x}$ ray was normal.

Subsequent CT scan showed:

- $\quad 3.9 \times 2.9 \times 5.3 \mathrm{~cm}$ size right inguinal mass with probable calcification. The fat planes between the mass and muscles were preserved.

- In right ischiorectal fossa, $1.6 \times 1.6 \mathrm{~cm}$ size similar mass was seen.

- In left inguinal region, $1.5 \times 1 \mathrm{~cm}$ size similar mass was seen.

The impression was of secondary deposits from the known primary lesion.

An oncological opinion was taken. An excision biopsy of right inguinal mass and an alpha protein level assay were suggested.

Excision biopsy of the right inguinal mass was performed. Macroscopic total resection of the non adherent mass was done. Histology revealed non seminomatous germ cell tumour, a malignant teratoma consisting entirely of papillary carcinoma of thyroid origin.

Repeat CT scans of the abdomen, pelvis and neck were done in view of need for later total thyroidectomy. The impressions were:

- There were no tumour remnants in the right groin.

- $\quad$ Right ischiorectal lymph node mass appeared malignant.

- Left inguinal mass was probably malignant.

- Thyroid gland was normal.

- There were no other metastatic lesions.

After discussion with the multi-disciplinary team, total thyroidectomy and, right ischiorectal and left inguinal lymph node mass excisions were done. (Figures 1-3) 


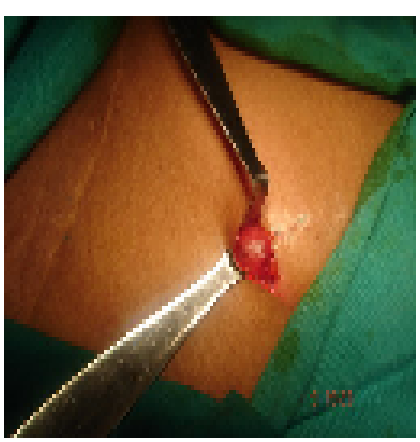

Fig. 1: Left inguinal dissection

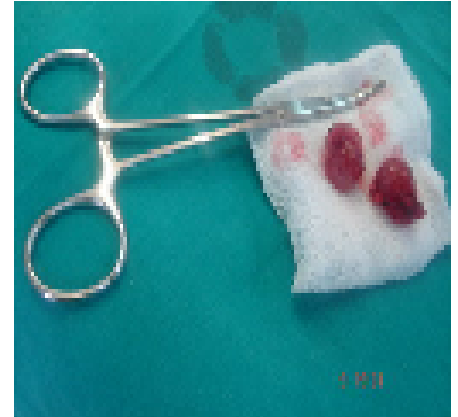

Fig. 2: Right ischiorectal nodes

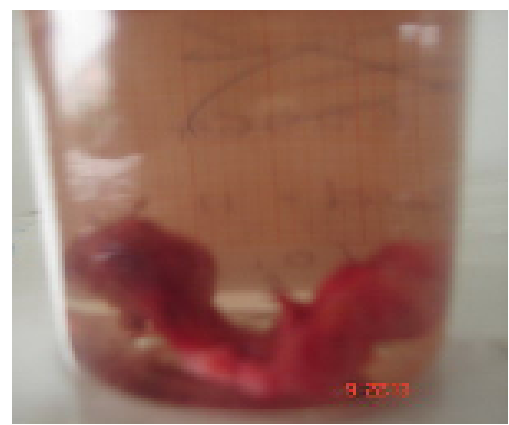

Fig. 3: Thyroidectomy specimen
Histology revealed:

- Right ischiorectal nodes: Malignant teratoma consisting entirely of papillary carcinoma of thyroid origin.

- Left inguinal mass: No tumour deposits.

- Thyroidectomy specimen: Normal thyroid gland.

On clinic follow up after radioiodine total body ablation, she was asymptomatic.

\section{Discussion}

Extragonadal germ cell tumours are rare tumours characteristically located in the midline from the pineal gland to the coccyx ${ }^{1}$. The incidence is 0.5 per 100000 population per year ${ }^{2}$. Occurrence in the sacrococcygeal region is reported to be less than $5 \%{ }^{1}$. They are commoner in males ${ }^{1}$. The only known risk factor is Klinefelter syndrome ${ }^{3}$. After complete excision, reported metastatic deposits are not known ${ }^{1}$.

In our patient, after image-assisted evaluation of the body, surgical excision of the lesions was performed. The resection margins were tumour free. The tumour markers were normal. Total thyroidectomy was performed prior to total body radioiodine ablation. On completion of the multidisciplinary approach for the cure, she is to be followed up in the outpatient clinic for surveillance of tumour recurrences.

\section{References}

1. Sachdeva K, Makhoul I, Curti B. Extragonadal germ cell tumours. e- medicine, updated: Aug 15, 2008. Available from:

http://emedicine.medscape.com/article/278174 -overview.

2. Dueland S, Stenwig AE, Heilo A, et al. Treatment and outcome of patients with extragonadal germ cell tumours--the Norwegian Radium Hospital's experience 1979-94. Br J Cancer. 1998; 77(2):329-35.

3. Hasle H, Jacobsen BB, Asschenfeldt $\mathrm{P}$, et al. Mediastinal germ cell tumour associated with Klinefelter syndrome. A report of case and review of the literature. Eur $J$ Pediatr 1992; 151(10): 735-9. 